\title{
SOBRE A LINGUAGEM EM GERAL E O QUE DIZ A LINGUAGEM DO HOMEM EM WALTER BENJAMIN
}

\author{
João Batista Moreira Araújo \\ A linguagem é uma fonte de mal entendidos. \\ Antoine de Saint-Exupéry \\ É uma verdade metafísica que toda a natureza \\ começaria a se queixar se Ihe fosse dada uma língua. \\ Walter Benjamin
}

\begin{abstract}
RESUMO
Nosso trabalho se fundamenta no texto Sobre a linguagem em geral e a linguagem do homem, de Walter Benjamin, onde Benjamin mostra a abrangência da linguagem sobre tudo o que se relaciona com o ser humano e como se dá a relação fundamental entre a Criação divina e a origem da linguagem, com sua relevância na propriedade nomeadora, perdida, com o abandono da "imediatidade na comunicação do concreto", o que dá origem à abstração, enquanto do conhecimento do bem e do mal deriva a palavra judicante.
\end{abstract}

Palavras-chave: Linguagem. Criação. Linguagem Nomeadora. Palavra Judicante. Abstração.

\section{ABOUT GENERAL LANGUAGE AND WHAT THE LANGUAGE OF THE MEN SAYS IN WALTER BENJAMIN}

\begin{abstract}
Our works founds in the text Sobre a linguagem em geral e a linguagem do homem, by Walter Benjamin, where Benjamin shows that language contain everything that is connected with the human been and how is the fundamental relation between divine Creation and the language's beginning, with weight in property that name things, lost, with abandonment of the "immediate in concrete's communication", what originate to abstraction, while the knowledge about Good and Evil emerges the judge word.
\end{abstract}

Key words: Language. Creation. Language Named. Judge Word. Abstraction.

\section{Introdução}

Nosso objetivo com esse artigo é tentar mostrar como Walter Benjamin entende a linguagem, como ela se origina e quais as implicações do autor acerca dessa origem. Nossa fonte de pesquisa foi o texto: Sobre a linguagem em geral e a linguagem do homem escrito pelo filósofo em 1916. A linguagem em Benjamin possui uma abrangência muito grande; visando melhor demonstrar os conceitos que 
ele utiliza no seu ensaio, dividimos o corpo do nosso artigo em seis tópicos: O que é linguagem; Os "meios" da linguagem; A origem da linguagem; O surgimento da palavra judicante; Origem da abstração e $A$ verdade está no nome.

\section{O que é linguagem?}

Língua ou linguagem, significa o princípio que se volta para a comunicação de conteúdos espirituais nos domínios em questão: na técnica, na arte, na jurisprudência ou na religião ${ }^{1}$.

Nessas palavras de Benjamin, a linguagem não envolve somente a comunicação, mas também todos os aspectos da vida humana. Tudo o que tiver relação com o homem possui uma linguagem. Mas nisso não vemos ainda nenhuma novidade em relação à concepção corrente de linguagem.

No entanto, se prestarmos atenção ao título do ensaio Sobre a linguagem em geral e a linguagem dos homens, veremos que Benjamin divide a linguagem em duas: "a linguagem dos homens" e "a linguagem em geral". Mas porque ele faria essa divisão? Haveria alguma linguagem que não seja humana? A resposta para essa última pergunta é sim - existe a linguagem humana e a linguagem das coisas. A respeito disso Benjamin comenta:

a existência da linguagem estende-se não apenas a todos os domínios de manifestação do espírito humano, ao qual, num sentido ou em outro, a língua sempre pertence, mas a absolutamente tudo. Não há evento ou coisa, tanto na natureza animada, quanto na inanimada, que não tenha, de alguma maneira, participação na linguagem, pois é essencial a tudo comunicar seu conteúdo espiritual. ${ }^{2}$

Logo, entendemos que a linguagem não se limita à vida humana, ela está presente em tudo o que existe: tanto na vida do homem, quanto no restante da criação.

$\mathrm{Na}$ concepção tradicional de linguagem, ao contrário dessa ideia, só existiria linguagem no âmbito humano. De acordo com essa concepção somente o ser humano teria capacidade para manifestar linguagem, de desenvolver uma forma de se comunicar. Essa falta de percepção sobre a importância da linguagem das coisas seria aquilo que falta às teorias modernas da linguagem. Pois não percebendo que

\footnotetext{
${ }^{1}$ BENJAMIN, Sobre a linguagem em geral e sobre a linguagem do homem, in: Mito e Linguagem. Trad. Susana Kampff e Ernani Chaves, 2011, (p. 49-50)

2 BENJAMIN, 2011, p. 50-51.
} 
as coisas também possuem uma linguagem, o conhecimento dessa mesma linguagem fica incompleto.

Mas a princípio, esse pensamento pode nos levar a fazer a seguinte pergunta: como as coisas se comunicam? Para responder essa pergunta, devemos ter em mente que não existe separação entre objetos, animais ou pessoas na natureza. Sobre isso Benjamin vai dizer:

a quem se comunica a lâmpada? A quem a montanha? E a raposa? - Aqui a resposta é: ao homem. Não se trata de antropomorfismo. A verdade dessa resposta se deixa ver no conhecimento, talvez também, na arte.

Para entender isso melhor, podemos pegar como exemplo uma obra de arte. Quando um artista observa um cavalo correndo pelo campo ou o pôr-do-sol, ele capta essa imagem através dos seus sentidos, e na pintura dessa imagem, que agora está na sua memória, busca expressar aquilo que sentiu ao visualizá-la. Essa pintura pode ser considerada, então, fruto da comunicação - concebida aqui de modo silencioso - entre o pintor e o seu objeto.

E Benjamin vai mais longe: "se a lâmpada e a montanha e a raposa não se comunicassem ao homem, como poderia ele nomeá-las? No entanto, ele as nomeia; ele se comunica ao nomeá-las". ${ }^{3}$ Eis aí a diferença entre a linguagem humana e a dos objetos. O que não existe nos objetos seria "uma linguagem nomeadora". Entendendo isso podemos dizer que, tanto o homem como as coisas são possuidores de linguagem. No entanto, "às coisas é negado o puro princípio formal da linguagem que é o som". ${ }^{4}$ Isso significa dizer que a linguagem das coisas é muda, é uma espécie de linguagem silenciosa; a linguagem dos homens, que é a linguagem nomeadora, é a linguagem sonora. A princípio pode parecer que existe uma oposição entre essas duas linguagens. Na verdade, o que existe aí é uma relação complementar entre a mudez das coisas e a sonoridade do homem.

\section{Os "meios" da linguagem}

Há dois termos na língua alemã que Benjamin utiliza no seu ensaio e que são fundamentais na sua compreensão de linguagem. Um desses termos é Mittel, que significa "meio para determinado fim"; o outro termo é Medium, que significa "meio

3 BENJAMIN, 2011, p. 55.

${ }^{4}$ Idem, 2011, p. 60 
enquanto matéria, ambiente e modo de comunicação." Este se refere ao meio em que ocorre a linguagem.

A concepção tradicional de linguagem - que Benjamin chama de concepção burguesa da linguagem - é a de que "o meio [Mittel] da comunicação é a palavra; seu objeto, a coisa; seu destinatário, um ser humano". ${ }^{2}$ Aqui ela é tratada simplesmente como intermediária da comunicação. É algo que serve para relacionar as coisas e o que se diz delas. De acordo com Epstein (1985), "a essência do signo parece ser a de um ente mediato, isto é 'algo que está por outra coisa'”. O signo seria então um simples instrumento, uma ferramenta utilizada para dar sentido àquilo que se quer comunicar. Mas se aquilo que se diz das coisas não são as coisas mesmas, o que é falado está esvaziado de sentido. Portanto, Benjamin defende que existe

outra concepção de linguagem que não conhece nem meio [Mittel], nem objeto, nem destinatário da comunicação. Ela afirma que no nome a essência espiritual do homem se comunica a Deus. ${ }^{6}$

Já que "a essência espiritual do homem é a língua mesma, ele não pode se comunicar através dela, mas apenas dentro dela."7 Nesse caso o meio (Medium) da linguagem é ela própria. Portanto, o homem não pode utilizá-la para se comunicar, mas só pode se comunicar dentro dela.

Os antigos gregos expressavam a identidade do espírito e da linguagem através da palavra Logos. Mas para Benjamin "a essência espiritual só é idêntica à essência linguística na medida em que é comunicável". ${ }^{8}$ Se através da palavra humana pudermos expressar aquilo que está na essência do seu objeto, existe aí uma identidade entre ambas. Mas se aquilo que eu digo é um conhecimento exterior, não existe então identidade entre o que é dito e o seu conteúdo espiritual.

Mas que tipo de linguagem é essa que faz parte da identidade espiritual do homem? A essa pergunta Benjamin vai responder que é "a linguagem em que ocorreu a Criação". 9

\footnotetext{
Idem, 2011, p. 55.

Idem, 2011, p. 55.

Idem, 2011, p. 56.

8 Idem, 2011, p. 52.

9 Idem, 2011, p. 62.
} 


\section{A origem da linguagem}

Benjamin se baseia na história bíblica da Criação divina para dar sustentação ao seu conceito de linguagem. Logo, para entendermos a origem da linguagem em Benjamin, temos que conhecer o livro do Gênesis, onde é contada a história da criação do mundo. Nessa parábola Deus cria o mundo e o homem através do poder da palavra.

A linguagem primordial tem origem com a própria Criação. No momento em que se dá a criação do mundo pela palavra de Deus surge a linguagem, já que é através do nome que Ele faz com que todas as coisas possam existir.

Deus utiliza o poder mágico da palavra e dá origem à toda a criação, mas Ele não nomeia a sua criação; o trabalho da nomeação é transferido ao homem. Este tem então a tarefa de nomear todas as coisas que existem. Naturalmente, no estado adâmico, o homem tinha o conhecimento necessário para nomear coisas e animais com seu verdadeiro nome: o Nome que revela a essência do seu objeto. Isso só foi possível porque ele possuía a capacidade de conhecer as coisas de modo imediato e verdadeiro.

O poder de nomear a criação também tem seu caráter mágico. Na verdade poderíamos dizer que a capacidade de nomear as coisas é um tipo de magia, já que a nomeação não é um simples ato de dar um nome qualquer a alguma coisa, mas é o conhecimento profundo da realidade dos objetos, onde o homem capta sua essência e daí o Nome se revela. E mais que isso, conhecendo o Nome e através dele se realiza a comunicação com o divino.

Essa magia também é uma capacidade dada por Deus. Podemos encontrar isso na seguinte passagem: "Então lahweh Deus modelou o homem com a argila do solo, insuflou em suas narinas um hálito de vida e o homem se tornou um ser vivente". ${ }^{10}$ Essa é a "segunda versão" da criação do homem, que se encontra no segundo capítulo do livro do Gênesis. A interpretação que Benjamin faz dessa passagem é a seguinte: nessa criação Deus coloca o sopro ou hálito de vida no homem "que é, ao mesmo tempo, vida e espírito e linguagem". ${ }^{11}$ Podemos entender, então, que a linguagem é tratada aqui como sendo o próprio espírito do homem. Com isso nosso filósofo quer mostrar a importância e a profundidade da linguagem:

\footnotetext{
${ }^{10}$ Gênesis. Bíblia Sagrada, capítulo 2, versículo 7.

${ }^{11}$ BENJAMIN, 2011, p. 60.
} 
ela representa a própria vida. Logo, entendemos que a linguagem permeia toda a realidade.

No seu livro Ler o livro do mundo (1999), Márcio Seligmann-Silva fala sobre a questão da linguagem em Walter Benjamin. Segundo esse autor - como o próprio título do livro sugere - é como se Benjamin percebesse o mundo como sendo um grande livro. Para esse estudioso, a possibilidade da leitura do mundo é real pois, sendo a realidade semelhante a uma obra literária, conhecer a sua linguagem é tudo o que seria necessário para compreendê-la. É por isso que podemos, entendendo sua linguagem, lê-lo.

\section{O surgimento da palavra judicante}

No Paraíso, as coisas e os animais eram conhecidos sem interferência de julgamentos, eram conhecidos espontaneamente, imediatamente, e isso se refletia na linguagem primordial. Depois do julgamento surgir no mundo - que tem sua representação no ato do homem ter comido "o fruto proibido" - perdeu-se o conhecimento verdadeiro das coisas e, consequentemente, de seus nomes. Quando o homem passa a julgar as coisas como boas ou más, ele cai do estado paradisíaco para o estado mundano.

O julgamento atrapalha o discernimento daquele que nomeia e, desse modo a verdade fica oculta, encoberta pelo manto da arrogância.

\footnotetext{
A árvore do conhecimento não estava no jardim de Deus pelas informações que eventualmente pudesse fornecer sobre o bem e o mal, mas sim como insígnia do julgamento sobre aquele que pergunta. Essa monstruosa ironia é o sinal distintivo da origem mítica do direito. ${ }^{12}$
}

Outra coisa importante que devemos notar é que Benjamin, aqui, questiona claramente o direito como sendo capaz de julgar justamente. Ora, tendo o direito surgido como sendo capaz de distinguir o bem do mal, está fadado ao erro.

"O conhecimento para o qual a serpente seduz, o saber sobre o que é bom e o que é mau, não tem nome. Ele é no sentido mais profundo, nulo". A falta de um nome para designar o conhecimento do bem e do mal, já nos revela sua característica fundamental: ele não ter existência própria, não existe aí uma essência para ser nomeada, pode-se dizer então que ele é nulo. Isso também fica claro se

\footnotetext{
${ }^{12}$ BENJAMIN, 2011, p. 69.
} 
entendermos que somente Deus tem o discernimento para diferenciar o bem do mal.

Quando o homem começou a julgar as coisas como boas ou más começou a se distanciar da realidade das palavras. A partir daí, foi se perdendo a relação entre as coisas e os seus respectivos nomes. Isso significa que "o pecado original é a hora de nascimento da palavra humana"13. O conhecimento do bem e do mal é um conhecimento exterior ao da linguagem. Com a descoberta do bem e do mal, a palavra perde sua magia imanente e se torna um falar externo, superficial, ou como diz Benjamin citando Kierkegaard, uma "tagarelice".

Agora, o homem não utiliza mais a linguagem nomeadora, que é a linguagem do verdadeiro conhecimento da realidade. A palavra, agora, acrescenta algo àquilo que é nomeado - ou seja, além da palavra não revelar o conhecimento acerca da realidade, ainda acrescenta algo diverso. É interessante notar que esse algo acrescido é colocado pelo próprio homem a partir do seu julgamento.

Depois que o homem cria a palavra judicante, se distancia do conhecimento verdadeiro da criação. E, ao se distanciar da linguagem primordial, os homens foram criando as diversas línguas que conhecemos hoje. Isso significa dizer que todas essas línguas (chinês, inglês, português, etc.) são apenas traduções da língua-mãe, que se perdeu há muito tempo. Os nomes agora são meros signos tentando dizer o que as coisas são. É a pura tagarelice que Benjamin coloca de forma quase poética na seguinte passagem:

Os signos necessariamente se confundem, lá onde as coisas se complicam. À servidão da língua na tagarelice segue-se a servidão das coisas na doidice quase como consequência inevitável. Nesse distanciamento das coisas, que foi a servidão, surgiu o plano de construção da torre de Babel e, com ela, a confusão entre as línguas. ${ }^{14}$

Com a queda do homem do estado paradisíaco a língua do homem se torna vazia e confusa. As palavras não significam mais o que a coisa quer dizer, perderam o seu sentido. Os nomes, agora, são colocados de forma aleatória: o que ocorre na criação de palavras são simples convenções que não tem significado verdadeiro. Por exemplo, as palavras house e casa se referem ao mesmo objeto, mas tanto house como casa não definem o que o objeto é. Para Seligmann-Silva (1999) "com a

\footnotetext{
${ }^{13}$ Idem, 2011, p. 67

${ }^{14}$ BENJAMIN, 2011, p. 69.
} 
'perda' da relação natural entre os elementos do mundo, tudo transforma-se em cifra de um saber enigmático".

\section{Origem da abstração}

Para Benjamin, o pecado original teria três consequências para o espírito humano. A primeira seria a de que quando o homem deixa a linguagem original ele transforma a linguagem em simples meio (Mittel), e desse modo também em signo; a segunda é que a partir do pecado original "se ergue (...) uma nova imediatidade, a magia do julgamento";

o terceiro significado, que se pode arriscadamente supor, seria o de que a origem da abstração enquanto capacidade do espírito linguístico deveria ser buscada no pecado original. ${ }^{15}$

Quando o homem inventa a palavra judicante, uma das coisas que vai surgir é a abstração. Esta, da mesma forma que o signo linguístico, é um distanciamento do real. Ou seja, na abstração mental existe uma separação entre a realidade e o pensamento. O vínculo entre o pensamento e a realidade só existe na mente daquele que pensa. A coisa é então "sobrenomeada" com o rótulo daquele que pensa. Esse rótulo é o conceito.

O conceito busca dar conta do real. Para tanto ele se apega a certas características dos objetos. Quando queremos conceituar algo, quando buscamos uma definição para tentar explicar o que as coisas são, fazemos uma generalização entre os objetos avaliados e disso tiramos alguma conclusão. Mas isso seria apenas uma aproximação daquilo que realmente ocorre no mundo. Já que cada ente é um ser único - não existe uma folha igual a outra na natureza, apesar de chamá-las todas pelo mesmo nome. Além do que, isso torna a comunicação algo distante do real. Nas palavras de Benjamin,

essa imediatidade na comunicação do abstrato instalou-se como judicante quando o homem, pela queda, abandonou a imediatidade na comunicação do concreto, isto é, o nome, e caiu no abismo do caráter mediado de toda comunicação, da palavra como meio, da palavra vã, no abismo da tagarelice. ${ }^{16}$

\footnotetext{
${ }^{15}$ Idem, 2011, p. 68

${ }^{16}$ BENJAMIN, 2011, p. 69.
} 
A verdade está na realidade. No entanto, não pode ser conhecida em sua totalidade como buscam os filósofos que tentam enquadrá-la dentro de um sistema. Ela não é fruto do trabalho intelectual ou filosófico. Ela faz parte da essência do real. $\mathrm{Na}$ Origem do drama barroco alemão, Benjamin coloca isso da seguinte forma: "O objeto do saber enquanto determinado pela intencionalidade do conceito, não é a verdade." Esta, não possui objetivos ou finalidades, como visa a produção conceitual - ela é não conceitual e não intencional. "A verdade é a morte da intenção". ${ }^{17}$ Já "o Nome é um ser livre de qualquer fenomenalidade". ${ }^{18}$

\title{
6. A verdade está no Nome
}

Por muito tempo, a ciência tem sido considerada um caminho seguro para se chegar à verdade, e desse modo ela é vista como um instrumento infalível. Mas sendo a ciência, uma criação humana, ela não pode ser perfeita.

\begin{abstract}
A unidade do saber, se é que ela existe, consiste apenas numa coerência mediata, produzida pelos conhecimentos parciais e de certa forma por seu equilíbrio, ao passo que na essência da verdade a unidade é uma determinação direta e imediata. ${ }^{19}$
\end{abstract}

Para Benjamin, a verdade não pode ser encontrada no experimento científico.

A verdade (wharheit) não é uma intenção, que encontrasse sua determinação através da empiria, e sim a força que determina a essência dessa empiria. O ser livre de qualquer fenomenalidade, no qual reside exclusivamente essa força, é a do Nome. ${ }^{20}$

Somente o Nome, que é livre de todos os aspectos fenomênicos, presentes na experiência sensível, pode ser essa força de sustentação. Ou seja, é através dele que se dá a possibilidade de um conhecimento do real, para a experiência sensível e para a descoberta das ideias.

Logo, "na contemplação filosófica a ideia (sic) se libera enquanto palavra, do âmago da realidade, reivindicando de novo seus direitos de nomeação." ${ }^{21}$ É por isso que Benjamin chama Adão de pai da filosofia, por que no Paraíso não era preciso se preocupar com o significado das palavras, não havia ainda uma criação conceitual e,

\footnotetext{
${ }^{17}$ BENJAMIN, Origem do drama barroco alemão. Trad. Sérgio Paulo Rouanet, 1984, (p. 58)

${ }^{18}$ Idem, 1984, p. 58.

19 Idem, 1984, p. 52.

${ }^{20}$ Idem, 1984, p. 58.

${ }^{21}$ Idem, 1984, p. 59.
} 
muito menos, uma multiplicidade de significados para cada palavra. No estado paradisíaco, o conhecimento se dava através da contemplação das essências.

Portanto, através da contemplação filosófica poderia se recuperar, por uma espécie de rememoração ou reminiscência, essa percepção do nome que se expressa através das ideias. Então, conclui Benjamin, que

a tarefa do filósofo é restaurar em sua primazia, pela representação, o caráter simbólico da palavra, no qual a ideia (sic) chega à consciência de si, o que é o oposto de qualquer comunicação dirigida para o exterior. ${ }^{22}$

\section{A linguagem da comunicação}

Essa comunicação que é utilizada pelo homem com um objetivo exterior ao da linguagem, parece ser a mãe da informação. Isso fica claro se entendermos que a informação só passa a existir quando a comunicação do homem é dirigida para o exterior, ou seja, ela é utilizada como simples meio (mittel) e tendo, também, um objetivo específico: acrescentar algo ao seu discurso. Mas esse acréscimo se dá de modo superficial, pois o entendimento das coisas não pode ser buscado fora da linguagem.

No seu texto $O$ narrador (1936), Benjamin fala como a linguagem da informação interfere no processo de extinção da arte de narrar:

Com a consolidação da burguesia - da qual a imprensa, no alto capitalismo, é um dos instrumentos mais importantes - destacou-se uma forma de comunicação que, por mais antigas que fossem suas origens, nunca havia influenciado decisivamente a forma épica. Agora ela exerce essa influência.

(...) Essa nova forma de comunicação é a informação. ${ }^{23}$

A informação agora influencia o próprio ato de se comunicar. A informação é fixa, limitada, engessada. Ao contrário, a narração, que era transmitida oralmente, é uma linguagem viva. Os narradores utilizavam a comunicação pra transmitir ensinamentos, adquiridos através da própria experiência, e desse modo o conhecimento era passado de modo natural.

\section{Conclusão}

A partir da origem teológica da linguagem em Benjamin, podemos ter pelos

\footnotetext{
${ }^{22}$ Idem, 1984, p. 59.

${ }^{23}$ BENJAMIN, 1993, p. 218.
} 
menos três implicações: o direito, vendo a si mesmo como portador do conhecimento para julgar o que é bom e o que é mau, não poderia estar mais enganado por sua incapacidade; o conhecimento científico, amparado pelo conceito, não detém a verdade absoluta e a informação, sendo uma forma de comunicação exterior, não traz nenhum conhecimento. Ou seja, em nenhum desses campos podemos encontrar a verdade. No entanto, através da contemplação filosófica ela pode se revelar por si mesma e de forma pontual, como o brilho de uma estrela, numa "iluminação profana". 


\section{REFERÊNCIAS}

BENJAMIN, Walter. Origem do drama barroco alemão. São Paulo: Brasiliense, 1984.

BENJAMIN, Walter. Obras Escolhidas: Magia e Técnica, Arte e Política. São Paulo: Brasiliense, 1993, p. 218.

BENJAMIN, Walter. Sobre a linguagem em geral e sobre a linguagem do homem. In: . Escritos sobre mito e linguagem. São Paulo: 34, 2011. p. 49-73

CALLADO, Tereza de Castro. "Da sacralidade barroca à iluminação profana do pensamento: linguagem, política e estado de criação" in:

Cadernos Walter Benjamin - Periódico de Filosofia $n^{\circ}$ 9, jul./dez. 2012, acessível no site: www.gewebe.com.br.

EPSTEIN, Isaac. O signo. São Paulo: Ática, 1985.

Gênesis. In: . Bíblia sagrada. São Paulo: Ave Maria, 2012. p. 49-51.

MEDEIROS, Mateus Gonçalves de. "Sobre a crítica do conhecimento de Walter Benjamin" in: Cadernos Walter Benjamin-Periódico de Filosofia $n^{\circ} 4$, jan./jun. 2010, acessível no site: www.gewebe.com.br.

SELIGMANN, Márcio. Ler o livro do mundo: Walter benjamin, romantismo e crítica poética. São Paulo: lluminuras, 1999. 